\title{
BUILDING A MORE COMPLETE DESIGN EXPERIENCE: PHILOSOPHIES AND REFLECTIONS FROM A SECOND YEAR Mechanical Engineering Design Project Course
}

\author{
Roger Carrick, Alex Czekanski, and Minha R. Ha \\ Department of Mechanical Engineering, York University \\ roger.carrick@lassonde.yorku.ca, alex.czekanski@lassonde.yorku.ca, minhareo@yorku.ca
}

\begin{abstract}
For undergraduate engineering students, earlier exposure to and training in the design engineering process hold much value for an enriched experience and an in-depth understanding of engineering design. Simultaneously, students in their earlier years require more guidance and frequent feedback to inform their own expectations of learning objectives, as well as develop effective learning strategies. This paper focuses on the design and implementation of a second year Mechanical Engineering "Mini-Design Project" course, which had four main goals: (1) provide students with their first "complete" design experience, allowing them to take a project from problem to produced solution; (2) integrate knowledge and skills from other courses in the curriculum; (3) allow for the enhancement of under-represented CEAB graduate attributes, particularly design and teamwork; and (4) prepare students for high performance in their capstone projects. Several learning needs were addressed: Effective teamwork skills, effective project management, and systematic practice of engineering design with an emphasis on the process. Students were placed in teams of 4-5 and given a design problem with specified evaluation criteria, and strict restrictions on construction materials. Students were given milestones throughout the term that encouraged them to follow the design process, as well as build, test and evaluate their designs. Mechanisms for creating and supporting design teams are described, and students' feedback and comments on these mechanism are discussed.
\end{abstract}

Keywords: Design, Experiential Learning, Problem Based Learning, Collaborative Learning, Course Creation

\section{INTRODUCTION}

Engineering as a profession is becoming increasingly complex and competitive. New technologies (advanced telecommunications and computer-aided engineering), and reduced barriers to international trade have allowed corporations to move engineering activities into emerging economies. These factors have allowed corporations to "unlock" traditional forms of organizational integration, vastly increasing the pool of engineers from which companies can draw. The reduced cost of operation in these emerging economies has put pressure on western countries to produce engineers that can encourage companies to keep high quality, technical engineering jobs local, instead of outsourcing. From the middle of the twentieth century, engineering education became increasingly focused on research and the engineering sciences, which led to decades of engineering graduates that are excellent scientists, but lack design, analysis and professional skills [1-4]. This is in opposition to the voices of industry and recent engineering graduates who feel that the attributes of design, teamwork, communication and problem solving are the most important [3][5][6]. Fortunately, there have been efforts to improve these skills in undergraduate programs, beginning with the introduction of Capstone Design courses, and later, cornerstone design courses to give first year students an introduction to the design process.

This paper describes the process behind the creation of a second year mechanical engineering "Mini-Design Project" course with the goal of creating a bridge between the first year introduction to the engineering design process, and the more complex, open-ended Capstone Design projects. Team design projects are an attractive method of achieving a variety of learning outcomes, with the most commonly cited goals being teamwork, design, communication skills and creativity or innovation [7].

Capstone Design courses take the form of large scaleoften multidisciplinary-team design project during a students' final year of study. Students at this point in their academic career have a wide range of theoretical knowledge, as well as engineering tools at their disposal. This allows these projects to be complex and gives students the opportunity to solve real-world problems, often sourced from community or industry partners.

Cornerstone Design courses have been introduced more recently, and were created in response to the apparent disconnect that first and second year engineering students were feeling from engineering practice [4]. The outcomes from these Cornerstone Design courses can vary greatly depending on the constraints placed upon the course, such as available time, resources and class size. Additionally, 
the prior knowledge and training of first year students can vary greatly, limiting the potential subject matter and scale of the projects. Thompson [8] proposes that Cornerstone Design courses can be roughly classified into three groups. First, are courses that teach engineering skills related to design, such as CAD, machining, drawing, etc. The second group consists of a semester-long design project where students are introduced to the design process. The third group contains elements of the first two groups where various aspects of design and engineering are introduced through small hands-on projects or exercises, such as reverse engineering. Despite these limitations, Cornerstone Design courses have had great success, and their introduction has helped to increase student satisfaction with their early education [4].

Design may not be at the top of the list attributes that engineers cite as most important in their professional careers [5], but this may be due to the variety of professional positions that engineers occupy, some of which may not directly contain elements of design. Design courses however, particularly project based design courses, are excellent methods of teaching and developing the top ranked attributes: teamwork, communication and problem solving.

\section{BACKGROUND}

\subsection{Pedagogy and Learning Theory}

Kolb's experiential learning cycle [9] is the model that is most commonly associated with teaching engineering design and the engineering design process. Kolb's cycle is composed of experimentation, concrete experience, reflective observation and abstract conceptualization. The iterative nature of this learning theory matches well with the engineering design process (such as VDI's systematic design process [10]) as a whole, where a product is designed, built, tested and analysed, and lastly reflected upon for possible future design improvement. The experiential learning cycle can also be applied at a smaller scale to the individual steps of the design process. For example, during the conceptual design phase, students will generate potential concepts, evaluate the concept against design goals and criteria, and use this knowledge to iterate their designs if they do not satisfactorily meet their requirements.

Kolb's experiential learning cycle has been implemented into several pedagogical methods. Of particular interest when discussing engineering design projects is Problem or Project-Based Learning (PBL). PBL was developed originally in medical schools in order to prepare students for professional practice in the 1970's. Professional associations at the time questioned if traditional teaching practices were adequately training students to deal with the real-world problems seen in practice. In PBL, students take on the role as primary investigators in the problem-solving procedures. Students are allowed to progress through the process in a way that simulates the natural learning style of students, inductive rather than deductive learning [9]. According to Barrows [11], a PBL model consists of the following basic characteristics:

a) Learning is student centred

b) Learning occurs in small groups

c) Teachers are facilitators or guides

d) Problems form the organizing focus and stimulus for learning

e) Problems are a vehicle for the development of problem-solving skills

f) New information is acquired through selfdirected learning

The PBL process (iteratively) generally follows the following steps:

1) Define the problem

2) Hypothesize solution methodologies

3) List what they know, what they need to know and what they need to do

4) Conduct research and analysis in order to update their lists from step 3

5) Propose solutions and assess their appropriateness

6) Critically reflect on the process used to generate a solution

Cooperative Learning (CL) is a teaching methodology focused on students working in teams to achieve a common goal; each student can only achieve their learning goal if the other members of the group achieve theirs [12]. The most commonly implemented model of CL is that of Johnson et al. [13], which specifies 5 basic conditions under which students must work:

1) Positive Interdependence

2) Individual Accountability

3) Face-to-Face Promotive Interaction

4) Appropriate use of collaborative skills

5) Regular self-assessment of group functioning

Research has shown that students taught in this method tend to have higher individual academic achievement and improvements in design skills, communication skills and group skills [14].

\subsection{Choosing the Right Design Project}

Choosing the correct subject for an engineering design project, particularly for first or second year students, can be challenging as discussed earlier. Literature describes some characteristics that design projects should include:

- Be challenging

- Be able to be completed within the timeline set by the course

- Contain sufficiently understood and documented subject matter 
- Emphasize the application of theory

- Make use of the engineering design process

- Be subject to specifications, standards and safety criteria

Dutson et. al. [15] identified five potential sources for design projects for use in engineering curriculums. These sources include:

- Hypothetical projects - in which course directors invent a project which can be tailored to meet the requirements of the particular class

- Student selected projects - in which students, sometimes with guidance, choose the problem they wish to solve, or the device they wish to design

- Research related projects - in which Professors propose design projects related to their research

- Industry sponsored projects - in which course developers solicit projects from industry to solve real-world problems

- Student design competition projects - in which projects are proposed by on-campus student design teams (eg. Formula SAE)

Each of these sources for design projects has their own advantages and disadvantages depending on the desired outcomes of the project, and each has been applied to Capstone projects. When working with Cornerstone design projects however, meeting the requirements of "understood subject matter" and "application of theory" is significantly more limiting. Searching for design projects from research, industry or student design competitions that can meet the scope requirements as well as contain only the theory and skills that first or second year students have been exposed to would be extremely difficult. Student selected projects are also difficult if the course developer would like to include the full design cycle (design and build) as students at that stage of their education have a poor understanding of the full scope of work required for projects. This leaves hypothetical projects as the most convenient choice for project topics as all aspects of the scope, technical requirements and resources required can be tailored to meet the needs of the course.

\subsection{Building Effective Teams}

Teamwork is often cited as the most desired outcome from team projects [7]. Teamwork is the primary mode in which professional engineers operate, and encouraging students to work well within a diverse team environment is of great interest for course developers. There are many models of effective teams that have been introduced [1618], and there are several key behaviours that each of them attempts to promote.

The first behaviour encouraged is interdependence [7]. In order for an effective group to complete their task they must rely upon on the work of the individual members of the team; if one member of the team does not complete their assigned task, it prevents the entire group from completing the project. There are varying levels of interdependence that teams can operate under from pooled interdependence to intensive interdependence. In pooled interdependence, students divide tasks, and complete them in parallel often with poor levels of communication. Intensive interdependence is considered the more desirable form, and each of the team members' divided work relies upon input from other team members' work, which encourages communication and coordination.

Trust is another important factor for effective teams. Trust itself can be defined in many ways, but the definitions most closely related to team effectiveness is the students' confidence in the abilities and trustworthy intentions of their team members [7]. Trust can be encouraged in teams through team-building exercises that help to reveal the abilities and strengths of the team members, as well as share past teamwork experiences.

The most cited and common complaint from students when working is teams is the concept of social loafing [7]. Social loafing occurs when one or more member of the team refuses to complete their fair share of the team's work. Self and peer evaluation has been found to be the most effective method of reducing social loafing in teams. When the individual contributions made by team members can be quantified and reported, social loafing can be largely eliminated. Another method of reducing social loafing is to encourage each team member to have a unique contribution to the team. Unique contributions are easiest to encourage in multidisciplinary environments such as Capstone projects, but can be more difficult in Cornerstone design projects as the students all have similar pre-existing skills.

\section{RESULTS AND DISCUSSION}

\subsection{Course Context}

The course described in the remainder of this paper is the second year mechanical engineering Mini-Design Project course at York University's Lassonde School of Engineering. This was the first year this course was conducted. The course was a 2-credit course, where standard courses are 3-credit courses. The course consisted of 1 hour of lecture a week which was dedicated to the study of engineering design case studies, and 2 hours of tutorials.

At this point in their academic career, students who participated in this course had taken the prerequisite physics and math courses, as well as two first-year introduction to engineering design courses. The introduction to design courses included exposure to the design process, design-for-x, various creative thinking and innovative design methodologies. These courses also included a team-based design project, however this project 
was taken only to the conceptual design phase, emphasising needs analysis and brainstorming techniques. Additionally, students had been introduced to CAD modelling in SolidWorks ${ }^{\mathrm{TM}}$ and were given the chance to 3D print their designs using MakerBot ${ }^{\mathrm{TM}}$ Replicators. Additional relevant courses include an introduction to Machine Element Design which was run concurrently with the Mini-Design Project course and Mechanics of Materials.

The goal of this course was to give students an opportunity to experience the complete design process as well as promote good teamwork practices. Integrating as many of the skills and theories to which students had been introduced up to this point was one of the primary driving factors in the choice of the project topic. By incorporating the various elements of the undergraduate curriculum into the project, students will be able to see practical applications of their theory as well as observe how interrelated their seemingly distinct core courses can be.

\subsection{Project Description}

In order to properly tailor the project to the requirements of the course, a hypothetical project was chosen. The premise presented to the student teams was that a spring manufacturer wished to investigate the possibility of using their springs to power an alternative energy vehicle. They were to take the role of an engineering design team hired to design and manufacture a proof of concept scale model vehicle powered by a spring. The teams' designs were evaluated in terms of mass and efficiency (distance travelled), with efficiency weighted at twice the value of mass. At the end of the term, the teams' vehicles competed in a competition-style event with a portion (10\%) of their final mark awarded depending on their relative performance compared to the other teams. A competition style event and marking scheme was included to encourage motivation, friendly rivalry between teams, and ensure that teams would continue to improve their designs, and not stop when they determined their design was just "good enough". The project was selected to integrate theory from physics, mechanics of materials and machine element design.

Constraints on the design and available materials constituted a major portion of the project. The final design was required to fit within a volume of 24 " X 20 " X 20 ", and the only external load that could be applied to the vehicle could come from a supplied "loading mechanism". The loading mechanism consisted of a weight on a cable fed over a pulley (see Figure 1). Teams had a choice of using a $5 \mathrm{lb}$ weight that could fall a distance of 12 " or a $2.5 \mathrm{lb}$ weight that could fall a distance of 24 ". The loading mechanism was presented as a theoretical "charging station" in which a spring powered vehicle's energy could be replenished. This constraint was placed on the project to ensure that all teams would have identical energy input into their system, as well as make the loading of the spring a non-trivial problem.

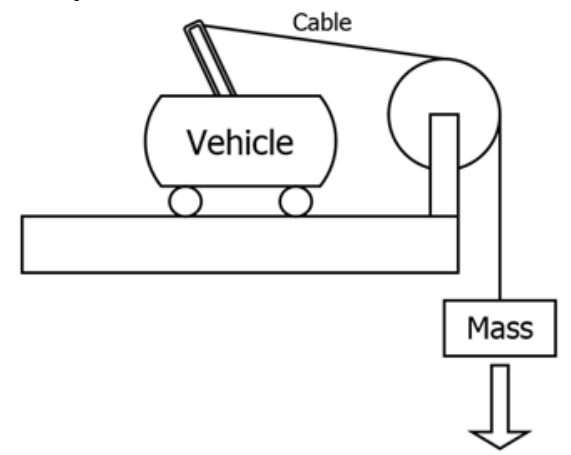

Figure 1: Schematic of loading mechanism

Each team was supplied with the same quantities of materials, and no other materials beyond the supplied materials could be used to build the vehicles. The materials supplied were:

- Compression springs (selection of 3)

- Tension springs (selection of 3)

- 2 sheets of acrylic ( $1 / 8$ " thick, 24"X24")

- $\quad$ PLA 3D-printing filament

- $50 \mathrm{M} 4$ panhead machine screws (8mm long)

- 50 M4 panhead machine screws (14mm long)

- $100 \mathrm{M} 4$ nuts

- 5mm 6061-T6 aluminium rod (6’ Long)

- 1 bottle of cyanoacrylate glue

Teams were required to choose only one spring to use in their final design. The springs available to the students were all chosen to have similar potential energy storage, and their maximum loads ranged from 12-25lbs. The maximum loads ensured that it would not be possible directly load the springs from the loading mechanism without some sort of mechanical advantage. Additionally, the bulk of the construction materials (acrylic sheets and PLA filament) were weak enough, and the forces of the springs high enough, that the design and analysis of the vehicle structure was non-trivial.

In order to successfully complete the project, students had to consider a variety of factors. They had to increase the amount of force supplied by the loading mechanism to fully extend/compress their spring. They also had to transform the potential energy of the spring into rotational motion, and include a gear train to reduce the torque and prevent the wheels from slipping. To achieve the best performance, students had to balance available torque, gear train efficiency, and weight.

In order to manufacture their vehicles, students had access to Lassonde's Sandbox 3D Prototyping Shop which contained several MakerBot ${ }^{\mathrm{TM}}$ Replicators, as well as an Epilog $^{\mathrm{TM}}$ M2 Fusion 75W laser cutter. Additionally, they had access to the student machine shop if they required any minor machining operations or hand tools. 


\subsection{Team Creation and Teambuilding}

A team size of 4-5 was chosen for this course as the literature highlights that larger teams can be more susceptible to social loafing, and teams smaller than 3 may not have all of the skills required to complete the task [19]. Of the three possible group formation methods (selfselected, instructor-selected or random), instructorselected was chosen as it is generally regarded as the most effective method [19][20]. Students were required to complete a questionnaire at the beginning of the term, and students were distributed based on a number of criteria. The primary criteria by which students were assigned groups was personality based. Students completed an online Myers-Briggs personality assessment, which assigns them one of 16 personality types. From these 16 personality types, students were placed into 4 categories based upon Keirsey's Temperament Sorter [21], Artist, Guardian, Rational and Idealist. Students were distributed in an attempt to match different personalities. While teams created with similar personality types tend to have better communication and reduced conflicts, teams with diverse personalities can have enhanced problem-solving skills as the weaknesses of one member can be complemented by the strengths of others [22]. Other criteria which were taken into consideration at a lower weighting during team formation were overall GPA, available free time, and previous skills. The online tool Team-Maker [20] was used to conduct the student questionnaire, and form the teams.

The first two weeks of tutorials were dedicated to encouraging teams to work together effectively. During the first tutorial, students were introduced to their teams, asked to choose a team name and given a personal introduction worksheet. The worksheet contained many of the same questions as the team formation questionnaire, and students were encouraged to share their personality profile results with their team if they felt comfortable. Additionally, students were asked to complete a team policies and expectations contract (modified from [19]). This contract outlined what was expected of each student when working in a team, such as communicating promptly and completing assigned work on time. The contract also contained a policy for dealing with social loafing or uncooperative members within teams. Students were encouraged to modify or add policies at their own discretion. The contract ensured that all students understood the policies set out by the course, and gave them a sense of ownership over the performance of their team. During the second tutorial, a teambuilding exercise was conducted using the LEGO Serious Play ${ }^{\mathrm{TM}}$ Platform. Students used a guided $\mathrm{LEGO}^{\mathrm{TM}}$ building experience to share previous team experiences, with a goal of helping to build trust between members of the group.

\subsection{Team Communication}

In order to promote a standard format for team communications, and help support collaboration, students were required to create a Slack ${ }^{\mathrm{TM}}$ account. Slack ${ }^{\mathrm{TM}}$ is an online collaboration platform that allows users to communicate in real time, share files and schedule meetings. Students were instructed to invite the course instructors to allow quick communication with the teams, as well as to allow instructors to review communication histories in the event of a team conflict.

Students were required to submit weekly meeting minutes for course credit. Students were given a meeting minutes outline following the PBL model which asked them to create lists of what information they know, what information they need to know, and finally a plan of action for each member that will allow them to complete the required deliverables for the next week. The students' goal for each week is to move points from their "need to know" list to their "known" list, as well as add any new items discovered to the "need to know" list.

\subsection{Peer-Evaluation}

Peer- and self-evaluation was included as the major tool in reducing social loafing, monitoring conflicts within teams and promoting collaborative learning. The Comprehensive Assessment of Team-Member Effectiveness (CATME) online peer evaluation instrument was used to rate the performance of each team member in terms of contributing to the team, interaction with the team, keeping on track, quality of work, and more. Peerand self-evaluation surveys were conducted 4 times throughout the term, each time after the submission of a major deliverable. Students were given participation marks for taking part in the surveys, and based upon the results of the final peer evaluation survey, a modifier was applied to their final report mark. The results of each of the peer evaluations was released to the students anonymously so that students could receive feedback regarding how the rest of the team perceived their contributions and communication. The CATME instrument highlights poorly performing students, as well as any major disparities between how a student and the rest of the team perceives their contributions.

\subsection{Design Process and Deliverables}

The structure of the deliverables was set up to follow the engineering design process. The design process highlighted for this course was the popular VDI 2221, Systematic Approach to the Design of Technical Systems and Products [10]. 


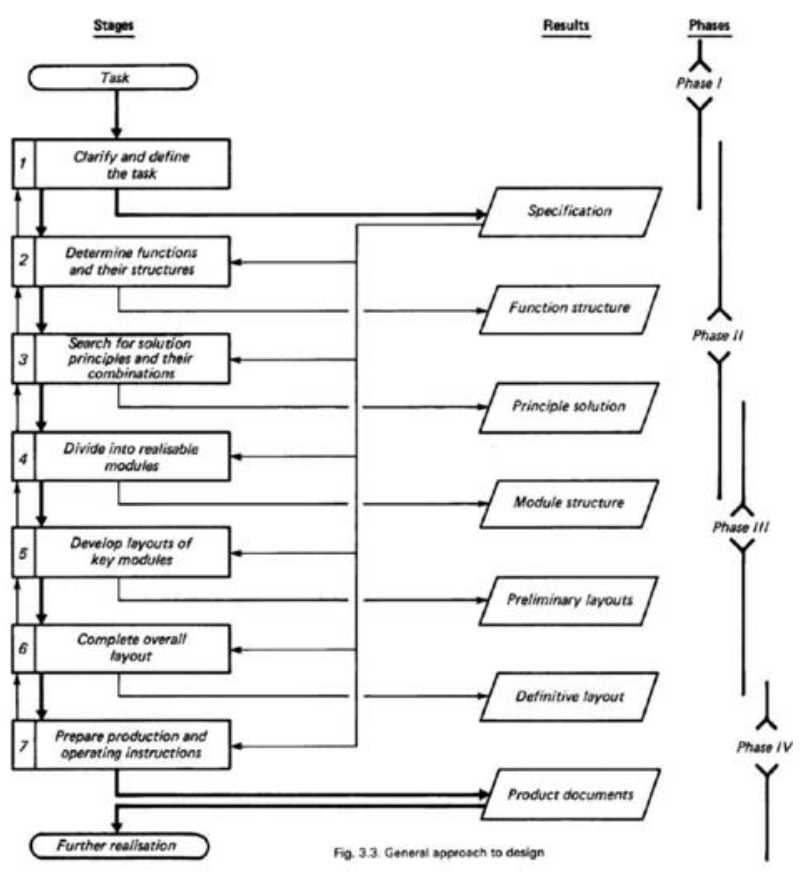

Figure 2: Design process as per VDI 2221 [10]

In previous experiences with design project courses, the authors observed students skipping major steps in the design process, or beginning with a final design in mind, and working backwards in the design process to tailor preliminary design steps to meet their desired design. This led to many students' designs failing to solve the desired problem, not meeting constraints, or arriving at a poorly optimized solution. In order to emphasise the importance of sequentially following the design process, reports corresponding to VDI 2221 design process "results" were collected at predetermined intervals during the term.

Following the submission and marking of each report, they were returned, and course instructors met with each team to discuss their reports, and any errors. Students were given time to reflect, ask questions, and make improvements to their ideas so that they could be used in subsequent design steps. These review sessions were essential in ensuring that students understood the subject matter and constantly worked to improve their designs.

Following the completion of the students' Definitive Layout, and 2 weeks before the final competition, students were required to build and test a prototype. The prototype was crucial in ensuring that students identified unforeseen errors in their design, limitations of the materials and/or manufacturing methods.

The final design report contained descriptions of the final design, CAD models, and testing results. It was also used as a final reflection on the overall design process. Students were asked to use the knowledge and experience that they had gained over the design process and reflect on how they would have approached each of the design phases differently.
Figure 3 shows examples of some of the completed student designs.
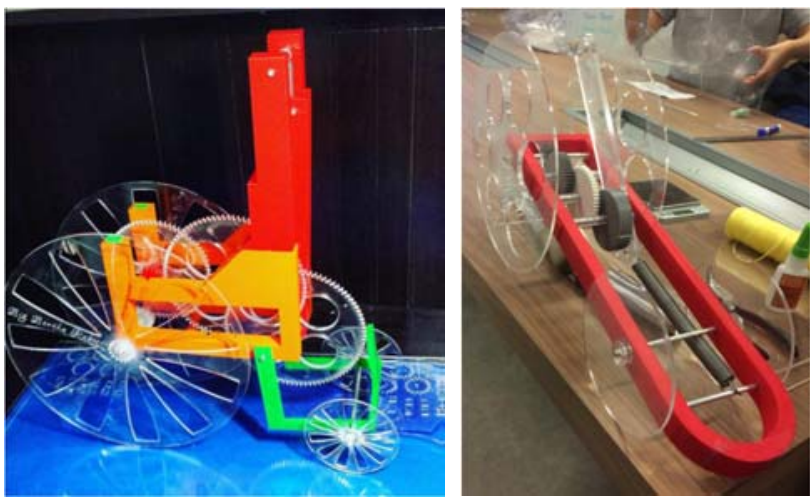

Figure 3: Examples of completed spring-powered vehicles

\subsection{Student Feedback}

In order to better understand student sentiment on the team building, teamwork, and peer evaluation initiatives instituted in this course, an exit survey was conducted at the end of the term. Students were informed that they would not be graded on the responses they gave on the survey, and the results were collected anonymously. 47 out of 58 students participated in the survey.

The first set of questions posed to the students, listed below, regarded using the CATME peer evaluation tool.

Q1) Did you find the CATME peer evaluation tool gave you an opportunity to become a better team member?

Q2) Did you find the CATME peer evaluation tool effective in assessing the quality of your teammates contributions?

Q3) Did you find the CATME peer evaluation tool effective for exchanging feedback related to teamwork?

\section{CATME Peer Evaluation Feedback}

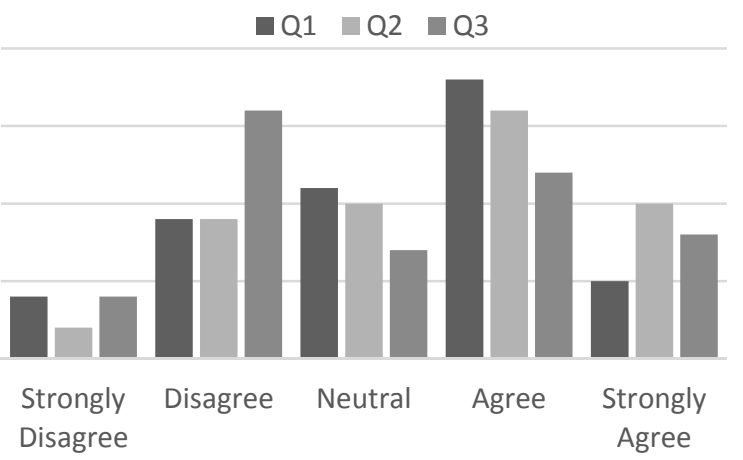

Figure 4: CATME peer evaluation feedback results 
Feedback concerning the CATME peer evaluation system was generally positive, but was far from unanimous. Students expressed concerns that peers would not give accurate responses to the peer evaluation questions, afraid to create conflict. Additionally, students would create "pacts" within teams pledging to always give each other top marks in the evaluations. This may explain why students did not feel that the tool was effective for exchanging feedback. From an instructor's perspective, the peer evaluation tool was able to highlight extreme cases of social loafing within teams, but may need some modification in how it is presented to students to improve overall accuracy and reception. Alternatively, the results from the peer evaluations could be kept confidential so that they may feel more comfortable giving honest reviews of their team members' performance, however they would lose an important tool for self-improvement.

The second set of questions, listed below, was related to how the teams were formed. Additional comments were collected for Q4.

Q4) Do you think that the team formation in this course was conducted fairly?

Q5) Do you think that creating teams with mixed personalities helped you to learn new teamwork skills?

Q6) Do you think that creating teams with mixed personalities helped the team successfully deliver a quality project?

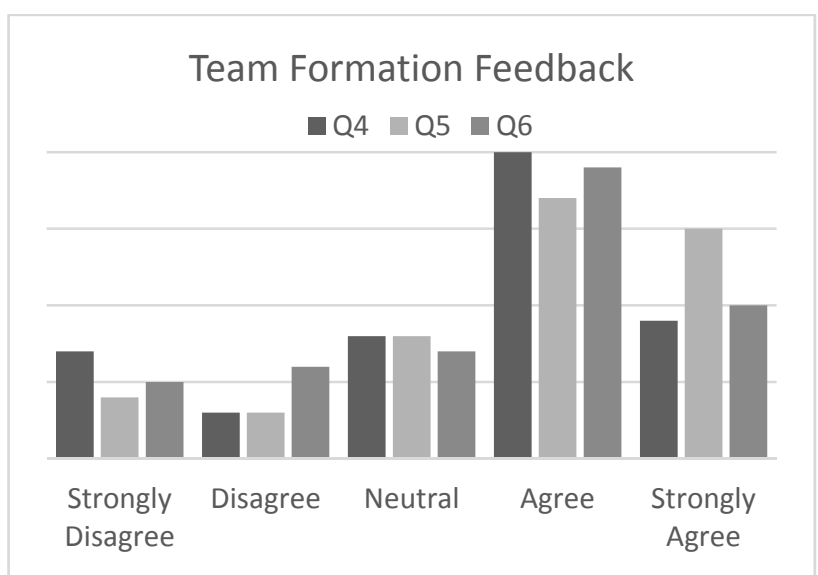

Figure 5: Team formation feedback results

Feedback revealed that students had a predominately positive reaction to the method of team formation. Students who rated the formation methodology as unfair described the method as "random" as they perceived some teams as being stronger in terms of the skills required to complete the project. In future iterations, instead of asking for overall GPA, grades in specific relevant courses will be used as a team formation criterion, as well as more indepth matching of students with different practical skills.

\section{CONCLUSIONS}

Developing a design project course for first and second year students can be difficult, but the tools available to course developers can help create a successful program. By understanding the skills and knowledge that the students have developed, a project can be tailored to be challenging, yet attainable. 3D printing and other rapid prototyping tools can allow projects to be designed, built and tested, all during a single term. By leveraging freely available online tools such as Slack ${ }^{\mathrm{TM}}$, Team-Maker and CATME, we were able to implement the major components of PBL and CL.

For most students, this was their first opportunity to fully design, analyze, build and test a design. Whether or not students were able to create a high performing vehicle, they learned valuable lessons in design and manufacturing, as well as practical applications of the theory presented in their engineering courses.

Including design activities, particularly team based design projects, during the early years of engineering curriculum can help to develop this skills and practices that industry is looking for.

\section{Acknowledgements}

The authors would like to thank the NSERC Chairs in Design Engineering for their support and the Lassonde School of Engineering for supplying the 3D printing filament for the students projects.

\section{References}

[1] R. Adams, D. Evangelou, L. English, A. D. DeFigueiredo, N. Mousoulides, A. L. Pawley, C. Shifellite, R. Stevens, M. Svinicki, J. M. Trenor, D. M. Wilson, "Multiple Perspectives on Engaging Future Engineers", Journal of Engineering Education, vol. 100, no. 1, pp. 48-88, 2011

[2] David S Strong and Warren Stiver, "Engineering design competency: Perceived barriers to effective engineering design education," in Proc. CEEA Canadian Engineering Education Association Conf., CEEC11, Andy Fisher (ed.) (St. John's, NL; 6-8 June 2011), 7 pp., 2011.

[3] Leland M. Nicolai, "Viewpoint: An industry view of engineering design education," International Journal of Engineering Education, vol. 14 no. 1 pp. 7-13, 1998.

[4] Clive L Dym, Alice M Agogino, Ozgur Eris, Daniel D Frey, and Larry J Leifer, "Engineering design thinking, teaching, and learning," Journal of Engineering Education, vol. 94, no. 1, pp. 103-120, 2005.

[5] Honor J Passow, "Which ABET competencies do engineering graduates find most important in their work?" 
Journal of Engineering Education, vol. 101 no. 1, pp. 95118,2012

[6] John S. Lamancusa, Jens E. Jorgensen, and Jose L. ZayasCastro, "The learning factory-a new approach to integrating design and manufacturing into the engineering curriculum," Journal of Engineering Education, vol. 86, no. 2, pp. 103$112,1997$.

[7] Maura Borrego, Jennifer Karlin, Lisa D. McNair, and Kacey Beddoes, "Team Effectiveness Theory from Industrial and Organizational Psychology Applied to Engineering Student Project Teams: A Research Review," Journal of Engineering Education, vol. 102 no. 4, pp. 472-512, 2013.

[8] Mary Kathryn Thompson, "Fostering innovation in cornerstone design courses," International Journal of Engineering Education, vol. 28, no. 2, pp. 325-338, 2012.

[9] Alice Y. Kolb and David A. Kolb, "Learning styles and learning spaces: Enhancing experiential learning in higher education," Academy of Management Learning \& Education, vol. 4, no. 2, pp. 193-212, 2005.

[10] "VDI-2221: Systematic approach to the development and design of technical systems and products," The Association of German Engineers, 1993-2005.

[11] H.S Barrows, "Problem-based learning in medicine and beyond: A brief overview," New directions for teaching and learning, vol. 68, pp. 3-12, 1996

[12] Barbara J Millis and Philip G Cottell Jr, Cooperative Learning for Higher Education Faculty, The Oryx Press., 1997 ( $1^{\text {st }}$ ed.), 282 pp., \{ISBN: 978-0897-74990-9\}

[13] David W Johnson, Roger T Johnson, and Mary Beth Stanne, "Cooperative learning methods: A meta-analysis," May 2000, Available as of April 9, 2016 from https://www.researchgate.net/publication/220040324_Coop erative_Learning_Methods_A_Meta-Analysis

[14] C. L. Colbeck J. M. Parente S. A. Bjorklund P T. Terenzini, A F. Cabrera, "Collaborative learning vs. lecture/discussion: Students' report learning gains," Journal of Engineering Education, vol. 90, no. 1, pp. 123-130, 2001.

[15] Alan J. Dutson, Robert H. Todd, Spencer P. Magleby, and Carl D. Sorensen, "A review of literature on teaching engineering design through project-oriented capstone courses," Journal of Engineering Education, vol. 86, no.1 pp. 17-28, 1997.

[16] M. C. Yang, and J. Yan, "An examination of team effectiveness in distributed and co-located engineering teams," International Journal of Engineering Education, vol. 24, no. 2, pp. 400-408, 2008.

[17]S. G. Adams, C. R. Zafft, M. C. Molano, and K. Rao, "Development of a protocol to measure team behavior in engineering education," Journal of STEM Education: Innovations \& Research, vol. 9, no. 1/2, pp. 13-20, 2008.

[18] R. Luechtefeld, D. Baca, and S. E. Watkins, "Training for self-managed student teams," International Journal of Engineering Education, vol. 24, no. 6, pp. 1139-1147, 2008.

[19] B. OLakley, R. M. Felder, R. Brent, and I. Elhajj, "Turning Student Groups into Effective Teams," Journal of Student Centered Learning, vol. 2, no. 1, pp. 9-34, 2004.

[20] R. A. Layton, M. L. Loughry, M. W. Ohland, and G. D. Ricco, "Design and validation of a web-based system for assigning members to teams using instructor-specified criteria," Advances in Engineering Education, vol. 2, no.1, pp.1-9, 2010.

[21]D. Keirsey, Please Understand Me II, Prometheus Nemesis Book Company, Del Mar, CA, 1998, 350 pp., \{ISBN:9781885-70502-0\}

[22]C. H. Amato, and L. H. Amato, "Enhancing Student Team Effectiveness: Application of Myers-Briggs Personality Assessment in Business Courses," Journal of Marketing Education, vol. 27, no. 1, pp.41-51, 2005. 